\title{
The Sociology of Phenomenological Structuralism
}

\author{
Paul C. Mocombe"
}

West Virginia State University, The Mocombeian Foundation, Inc.

\author{
DOI: $10.36348 /$ jaep.2021.v05i02.001 \\ | Received: 16.01.2021 | Accepted: 27.01.2021 | Published: 04.02.2021 \\ *Corresponding author: Paul C. Mocombe
}

\section{Abstract}

This work highlights the sociology behind Paul C. Mocombe's theory of phenomenological structuralism. The author posits a structurationist sociology that is tied to the theory's emergent logico-metaphysical materialist account regarding the constitution and perpetuation of the multiverse, consciousness, society, and the individual.

Keywords: Structurationism, Praxis, Panpsychism, Social Class Language Game, Phenomenological Structuralism, ORCH-OR Theory, Univon Multiverse Hypothesis, Free-will, Determinism, Haitian Epistemology, Consciousness Field Theory, Conscious Electromagnetic Information Theory (CEMI).

Copyright ( $) 2021$ The Author(s): This is an open-access article distributed under the terms of the Creative Commons Attribution 4.0 International License (CC BY-NC 4.0) which permits unrestricted use, distribution, and reproduction in any medium for non-commercial use provided the original author and source are credited.

\section{INTRODUCTION}

This work highlights the sociology behind Paul C. Mocombe's theory of phenomenological structuralism. The author posits a structurationist sociology that is tied to the theory's emergent logicometaphysical materialist account regarding the formation, constitution, and perpetuation of the multiverse, consciousness, society, and the individual.

Paul C. Mocombe's structurationist theory of phenomenological structuralism, building on and synthesizing a form of M-theory with, mathematical elements of univon multiverse hypothesis, the quantum computation of ORCH-OR theory, Black Hole Big Bang Theory (BHBBT), structurationism, and the multiverse ideas of Haitian ontology/epistemology and quantum mechanics abductively posits that spacetime is fundamental; and consciousness is an emergent fifth force of nature, a field of consciousness (the consciousness field-CF) composed of an emergent quantum material substance/energy, psychion, the phenomenal property, qualia or informational content, of which is recycled/replicated/entangled/superimposed throughout the multiverse and becomes embodied via the microtubules of neurons of brains and aggregate matter of multiple worlds to constitute mind. Mind (composed of the personal and collective unconscious, and the sense-experience of the emerging ego held together by the brain's electromagnetic field generated by the periodic discharge of neurons), in turn, is manifested in simultaneous, entangled, superimposed, and interconnecting material resource frameworks, multiple worlds, as praxis or practical consciousness of organic life, the content of which in-turn becomes the phenomenal properties, qualia, of material (subatomic particle energy, psychion) consciousness that is recycled/replicated/entangled/superimposed via the consciousness field throughout the multiverses upon matter disaggregation. In other words, existence precedes essence; but essence is emergent and eternal, and comes to constitute a fifth force of nature, a field of consciousness for Being production (the consciousness field), through the phenomenal properties, qualia (personal and collective unconscious), of neuronal subatomic particles, psychion, which are recycled/replicated/superimposed/entangled throughout the multiverse and give human actors their initial (essential) practical consciousness that they organize and reproduce in replicated, entangled, and superimposed material resource frameworks. On this physics Mocombe builds his systemic philosophy, sociology, and psychology called, phenomenological structuralism. This work highlights the structurationist sociology associated with Mocombe's theory of phenomenological structuralism.

\section{Background of the Problem}

Three major approaches dominate sociological theory: structural functionalism, conflict theory, and symbolic interactionism. Symbolic interactionism is a microlevel approach that focuses on symbols and how people interact with each other by recursively organizing and reproducing these symbols (and their meanings) in their everyday lives to constitute society. 
Paul C. Mocombe., J Adv Educ Philos, Feb, 2021; 5(2): 32-51

Structural functionalism and conflict theories are macrolevel approaches, which focus on the constitution of society from the perspective of institutions. Structural functionalism views society as a cohesive whole with interdependent parts, i.e., people, institutions, etc., which contributes to society's functioning as an organic whole. Whereas structural functionalists emphasize the social cohesiveness of society, conflict theory, on the contrary, highlights competition between unequal groups and power as the basis for the constitution and ever-changing nature of society.

All three perspectives are problematic from the standpoint of social agency. Symbolic interactionism emphasizes the actions of individuals as the basis for the constitution of society at the expense of the overarching structures, i.e., institutions, that stabilize and give individuals their practical activities. Structural functionalism highlights the cohesiveness of the groups in society at the expense of differentiating actions and conflicts amongst and between them. Conversely, conflict theory emphasizes the power relations between and amongst groups and their emerging conflicts at the expense of their social cohesion.

Moreover, since the 1960's with the advent of postmodern and post-structural theories into the theoretical discourses of social science academics a new struggle regarding the origins and nature of agency, identity, and consciousness vis-à-vis the aforementioned problematics has dominated social science and philosophical theories. The issue centers on several factors raised by postmodern and post-structural thinkers in the likes of Michel Foucault, Jacques Derrida, and Jacques Lacan against the structuralism of the sciences, 1) they question the validity regarding the Cartesian rational individual, which Foucault and Derrida deny in favor of their attempt to dissolve the subject altogether; 2) they question the interdependency of the constitution of a stable structure and a distinct subject with agency, in denying the latter they undermine the former; 3 ) they question the status of science; 4) finally, they question the possibility of the objectivity of any language of description or analysis. Although these factors raised in the writings of Jacques Lacan, Jacques Derrida, and Michel Foucault are theoretically legitimate and have posed tremendous problems for the social sciences and their constitution as a science based on the notion of a stable structure constituted by stable subjects with agency. These problems have not adequately been addressed by Marxist social theorists in the social sciences like Louis Althusser, Pierre Bourdieu, Jürgen Habermas, Anthony Giddens, and Marshall Sahlins working to resolve this structure/agency issue by attempting to synthesize the rationality of the individual with the phenomenological discourses of the former theorists, and Marxist and structural Marxist philosophy.
The structure/agency debate in the social sciences emphasize the rational origins of the reproduced and transformed social actions of social actors that constitute a social structure: are social actors determined and driven by internal invariable structures of the mind [1-3], or are social actors automatons determined and driven by external relational structures of signification [4-6]. Thus, in the social scientific form of the debate, biological determinism, i.e., innate senses of anything, as well as the Lévi-Straussian sense, i.e., innate structure of the mind, were out rightly rejected. Also, the idea that social actors are irreducibly situated subjects who act and react based on rational calculations as they respond to particular external social processes (social structure) or stimuli was for the most part dismissed. Total rationality was viewed as an impossibility given the inability of social actors to either know all the choices available to them in the present or know the complete future outcomes of those choices. This made rationality necessarily relative to a frame of reference or structure of signification, which rejects the indeterminacy of meaning and decentered subject of postmodern/post-structural theorizing.

Hence, the focus in the study of action and interaction in the social sciences was thus not a matter of denying or minimizing the rational potential of social actors, but expressed rather an urgent need to understand where 'the system' or structure that limits their knowledge and stabilizes society "comes fromhow it is produced and reproduced, and how it may have changed in the past or be changed in the future [7]". In other words, thinkers plagued by this debate, sought "to explain the relationship(s) that obtain between human action, on the one hand, and some global entity which we may call the system, [or social structure, structure, or culture] on the other" [7], when the latter (i.e., the system) is not a necessary reflection of neither biology, nor the structure of the mind, but an external force of rules of conduct, i.e., categorical boundaries, that stabilizes society and thereby constitute the identity of social actors as argued by Talcott Parsons and Louis Althusser.

From roughly 1975 to the present, an enormous strand of critical writings, expounding a great many strands of theoretical schools of thought, combined to challenge this post-World War II structuralist matrix which denied alternative agencies, outside the relational logic of a structure, system, or culture to social actors. Some were advanced by rationalist thinkers seeking to preserve the idea of individuals as solitary thinkers who act in a purposive rational way, while others were offered by theorists dedicated to preserving the tenets of structuralfunctionalism and structural-Marxism while explicating the functional role of difference or the variability of practices amongst social actors within social structure not as an invariable by-product of the mind but as an external unified structure of signification or system. 
Paul C. Mocombe., J Adv Educ Philos, Feb, 2021; 5(2): 32-51

Considering this action-oriented response to account for the different provinces of meaning within systems or structures of signification, the term praxis or structurationist theorists will serve as the dominant label for the arguments expounded in opposition to Parsonian structural-functionalism and variants of structural Marxism by prominent theorists such as Pierre Bourdieu, Marshall Sahlins, Anthony Giddens, and Jürgen Habermas [8, 7]. These arguments are complex, and to examine them together is necessarily to do violence to the purity of notions advanced separately by various authors. The exercise is nevertheless useful at least for revealing their main and common objective, i.e., to resolve the structure/agency debate of the social sciences.

\section{The Structurationist Response and its Problems}

Structural-functionalists and StructuralMarxists in attempting to understand social action (i.e., praxis) within social structures of signification privilege social relations and reproduction via linguistic and symbolic representation over biological determining elements (i.e., race, sex, etc.), for meaning, human action, and consciousness constructions. In doing so, however, they fail to account for the origins and nature of the different provinces of meaning, human action, and consciousness existing within, but at the same time, outside the relational or dialectical prescribed logic of the social structure (structural reproduction and differentiation). Neo-structuralists or structurationists in the likes of Pierre Bourdieu [9-11], with his theory of practice (habitus or constructivist structuralism), Marshall Sahlins [12-14] through mythopraxis, Anthony Giddens [15] through his theory of structuration, and Jürgen Habermas [16-18] with his theory of "communicative action," however, attempt to do just that, "explain the relationship(s) that obtain between human action, on the one hand, and some global entity which we may call the system, [or social structure, structure, or culture] on the other" in order to capture the nature of social action, reproduction, transformation, and differentiation within structures of signification. They attempt to do so, for the most part, through "the central notion of the 'duality of structure' which refers to 'the essential recursiveness of social life, as constituted in social practices: structure is both medium and outcome of the reproduction of practices", [19]. That is, structures are not only external to social actors, but are internal rules and resources ("form of consciousness") produced and reproduced by actors "unconsciously" (intuitively) in their practices. From this perspective, accordingly, structure, i.e., culture or, sociological speaking, social structure, "may set conditions to the historical process, but it is dissolved and reformulated in material practice, so that history becomes the realization, in the form of society, of the actual [(embodied rules)] resources people put into play" $[13,14]$. In this understanding, the structure is not an epiphenomenon of the structure of the mind, but is a result of the internalization by social actors of external (social structural) rules of conduct which are sanctioned, recursively (re) organized, reproduced, and differentiated in material practice. Thus, social structure, human action, meaning, and consciousness are mutually constituted and united together as "practical consciousness," i.e., a duality.

Ostensibly, like structuralism, structural functionalism, and structural Marxism, the structurationist response to account for the nature of human action within structures of signification, however, is also problematic. That is, the central notion of the duality of structure prevents praxis theorists from accounting for the origins and relational nature of the variability of praxis or "practical consciousnesses" within a particular structure of signification. That is to say, the part/whole dialectic of the "duality" concept cannot account for the origins of alternative "practical consciousnesses" that arises as a result of 1) the drives and sensibilities of the body and brain, 2) the drives and impulses, phenomenal properties, qualia, of embodied recycled/entangled/superimposed subatomic particles, psychions, and 3) the deferment of meaning in egocentered communicative discourse during the internalization process as suggested by postmodern and post-structural theory [20]. In essence, structurationists are only able to account for the dialectic of 4) structural reproduction and differentiation stemming from the means and mode of production of a society and their ideological apparatuses [20].

\section{Pierre Bourdieu}

The central notion of the duality of structure in Pierre Bourdieu $[9,10]$ is described as a "dialectic of objective structures and incorporated structures (habitus) which operates in every practical action" [9]. Action, therefore, is a result of the habitus of individuals, an "embodied history, internalized as a second nature and so forgotten as history . .." (56); a "system of structured, structuring dispositions" (52) that are "deposited in each organism in the form of schemes of perception, thought and action [,]" (54) derived from "the conditionings [(fields)] associated with a particular class of [material] conditions of existence ..." (53). In short, in his application of this theory to capitalist society in his work Distinctions 1984 cultural, economic, political, and social capital become the system of structured, structuring dispositions that are deposited in social actors in their form of schemes of perception, thought, and action that differentiates them and their conditioning fields from each other in the society. More concretely speaking, the bourgeois class of capitalist society possesses the capital forms, i.e., linguistic, social, economic, cultural, and political capitals, which constitute the social structure of modern societies and gets distributed throughout the society and differentiates the middle and working classes from the upper-class of owners and high-level executives based upon the amount of capital they possess in their material conditions. Albeit, all classes in the society 
Paul C. Mocombe., J Adv Educ Philos, Feb, 2021; 5(2): 32-51

seek to possess the capital of the bourgeois upperclasses whose institutions or ideological apparatuses transmit these structuring dispositions to them.

Although Bourdieu's materialization of social structure by synthesizing the objectivity of the latter with the subjectivity of action is able to capture the actual nature of human social action and societal reproduction, the movement of the body as a result of the embodiment of a "system of structured, structuring dispositions" within "fields" associated with a particular class of material conditions, his theory is only able to capture the origins and nature of structural reproduction and differentiation produced by the relational logic and praxis of the "[(capitalist)] system of structured, structuring dispositions" and not the origins and role of difference arrived at through the deferment of meaning in the incorporation process and the other two processes I have highlighted above. In other words, Bourdieu's praxis response is unable to capture the relation and role of the different means (practical consciousnesses) of organizing a "field," which arises because of the deferment of meaning in the internalization "of schemes of perception, thought and action derived from the conditionings" within a dominant structure of signification. That is, the central notion of the duality of structure prevents Bourdieu from accounting for the origins and relational nature of the variability of praxis or "practical consciousnesses" within a particular structure of signification. The part/whole dialectic of the "duality" concept cannot account for alternative "practical consciousnesses" that arises as a result of not structural differentiation, but the drives of the body, phenomenal properties of embodied subatomic particles, and the deferment of meaning in ego-centered communicative discourse during the internalization process of signifiers [16-18, 21, 20]. In a word, he is unable to account for Jacques Derrida's notion of différance, alternative structures of signification and actions that are outside the structuring structure of capitalist structural differentiation, on the one hand; and Mocombe's [20, 22] drives/impulses, phenomenal properties, vis-à-vis the body and embodied subatomic particles, on the other.

\section{Marshall Sahlins}

In Marshall Sahlins's [12-14] cultural structuralist history, the interrelationship is also between structures of significance and social action. That is, action, "structure of the conjuncture," emerges from the dialectic between culture (structure) and the cultural schemes in the individual, prefigured myths (mythopraxis) in his application of his theory to the ancient Hawaiians or prefigured "interests" in the case of contemporary "man," which are actually symbols and categories constituting a received system that gives persons, events, and objects their historical effect [13, 14]. So that, situations are ordered by culture (structure), and history, or agency, is the product of structures of significance: the recursively organized and reproduced cultural schemes (habitus in Bourdieu's approach) of the individual or social actor "dissolved or reformulated" in the material world (7).

Like Bourdieu, Sahlins is able to demonstrate the material nature of social action derived from the internalization of external structures of signification. However, also like Bourdieu, he is unable to account for the relation of the analytics (mental states) of an individual actor vis-à-vis the different provinces of meaning within the structure of signification, which arises as a result of the drives of the body, phenomenal properties of embodied subatomic particles, and the deferment of meaning in ego-centered communicative discourse. In other words, as in the case of the ancient Hawaiians, who Sahlins argue assumed Captain Cook to be a god because their internalization of the mythical structures of signification which structured their social action or gave them their historical effect posited such a being, he is unable to account for the nature and relation of those Polynesians who upon internalizing this "mythical reality" rejected it for another interpretation, i.e., he was a "thug" seeking to steal their land, women, children, and resources. Sahlins' conflating of action and structures mutual constitution prevents such a materialized happening or conclusion. The part/whole dialectic by which Hawaiian consciousness is constituted via the structure of the conjuncture of their mythopraxis in Sahlins' theorizing cannot account for how the Polynesians could reach any other conclusion outside that which is determined by their dialectic totality, mythopraxis, "which are actually symbols and categories constituting a received system that gives persons, events, and objects their historical effect."

\section{Anthony Giddens}

Just the same, Anthony Giddens [15], like Bourdieu and Sahlins, also highlights this "duality of structure." His theory of structuration, which has no obvious single statement of explanation, is a social ontology describing what it means to be an individual invested with "practical consciousness"-a structure's or culture's rules and resources. Thus, "one of the main propositions of structuration theory is that the rules and resources drawn upon in the production and reproduction of social action are at the same time the means of system reproduction (duality of structure)" (19). Action in this understanding is a result of the structural properties of social systems consciously and unconsciously manifesting themselves in the practices that individuals, in order to maintain their ontological security, recursively organize and reproduce (25).

Whereas Giddens, unlike Bourdieu and Sahlins, posits difference through the notion of structural differentiation as a result of the threat to a social actor's ontological security, he is still unable to account for the origins, nature, and relation, within the dominant structure of signification, of those who upon internalizing a structure's rule of conduct which are 
Paul C. Mocombe., J Adv Educ Philos, Feb, 2021; 5(2): 32-51

sanctioned reject them for ontological insecure ways of reproducing their material resource framework. In other words, Giddens, through his notion of "ontological security," is able to demonstrate how and why social actors choose to reproduce the external structural properties of social systems, which after a while simply become a second nature forgotten as history. What he is unable to demonstrate, however, given his notion of the "duality" of structure, is how alternative practices may emerge, and the relation and functioning of these practices to the dominant social system.

\section{Jürgen Habermas}

Jürgen Habermas's [16, 17] ought to be "organic" conclusion regarding the constitution of present modern conditions, unlike Giddens, account for the constitution of alternative practices through the distinction he draws between system and lifeworld. Habermas's evolutionary social ontology, "communicative action," is based on the Weberian understanding of the rationalization process in modernity. That is to say, for Habermas the rationalization process in modern communicative discourse has historically developed into a differentiated lifeworld of varying cultural traditions, networks of solidarity groups, and institutions of socialization, "enframed" by, but differentiated from, the rational formation of the secular systems of economy and politics derived from linguistically arrived at "mutual understanding" amongst these varying groups and institutions. This Durkheimian "organic solidarity" which emphasizes mutual cooperation, takes différance, or the variability of alternative practices derived through the deferment of meaning in ego-centered communicative discourse, to be the basis for the constitution of modern society. For the rational system of economy and politics in the Habermasian sense is distinguished from the lifeworld of a myriad of meaningful subjective pragmatic positions or categorical boundaries, which it "organically" stabilizes and governs. This, according to Habermas, like Emile Durkheim, differentiates modern societies from primitive ones, which "mechanically" marginalized all differences and différance for the underlying "sacred rules" governing meaning that is the social structure.

Like the traditional structural structurationism of Bourdieu, Sahlins, and Giddens, which views the (post) modern social structure or system as a reified symbolic order in which its representations, practices, and meanings are fixed and must be internalized or embodied by social actors as their practical consciousness, part/whole relation, my attempt to understand the constitution of modern society as difference and différance assumes that the distinction between the lifeworld and its manifestation as a system (organized around the mode of production), is more enduring just as in primitive societies. Habermas, who refers to this notion as "the colonization of the lifeworld," sees it as a "crisis" in the constitution of modern society; I see it as the more valid means or framework to understanding the nature of systems and social integration up till this point in the human archaeological record.

To put it simply, whereas Habermas, building on the works of George Herbert Mead, Emile Durkheim, and Max Weber, sees the "linguistification of the sacred, as an unfettering of the rationality potential of action oriented to mutual understanding" $[16,17]$, i.e., "communicative action" between subjective positions of the lifeworld within the rational agreed upon boundaries of the economic and political system, which distinguishes modernity from "primitive societies." I, building on the structural duality outlined by the more traditional structurationists, view Habermas's liberal position and the constitution of modern society in terms of a re-sacrilization of society based on the substantive and purposive rationality of the Protestant ethic and the spirit of capitalism. That is, (post) modern society is no different from primitive ones. It is an enchantment of the world via the Protestant Ethic and the spirit of capitalism. As such, so-called modern society is a Durkheimian "mechanical solidarity" re-sacrilized through the universal claims embedded in a substantive and purposive-rationality, which is an avatar of a sacred linguistic worldview, i.e., the cultural or social structural conditions of Protestantism and its discursive practice the spirit of capitalism and its modes of production.

This mechanical constitution of modern society via bodies (practical consciousnesses), language, ideology, ideological apparatuses, and communicative discourse structuralizing the class division and social relations of production of the Protestant ethic and the spirit of capitalism worldview on the earth, captures the constitution of modern society in our universe, galaxy, and the earth, through the Habermasian rejected notion of "the colonization of the lifeworld." Habermas fails to realize that the lifeworld he speaks of is structuralized and differentiated within the systemic dialectic, class division and social relations of production, of the Protestant Ethic and the spirit of (postindustrial) capitalism, which juxtaposes his embourgeoised position within the system against the differentiated lifeworld of the underclass masses, he is theorizing about. That is to say, the lifeworld is not magically protected from the systemicity of the Protestant Ethic and the spirit of capitalism by which modern society is constituted. It is also structured and differentiated within the systemicity, class division and social relations of production, of the Protestant Ethic and the spirit of capitalism via bodies, language, ideology, ideological apparatuses (media, education, etc.), communicative discourse, and the mode of production of the upper-class of owners and high-level executives. It is within this (their enchantment) mechanical constitutive framework that the origins and 
Paul C. Mocombe., J Adv Educ Philos, Feb, 2021; 5(2): 32-51

relations of alternative practices arrived at as a result of an individual actor's stance/analytics vis-à-vis the drives of the body, drives/impulses (phenomenal properties) of residual past consciousnesses of recycled subatomic particles, and through the deferment of meaning in ego-centered communicative discourse must be understood. It is not that these alternative practices arrived-at, ready-to-hand, unready-to-hand and presentat-hand, vis-à-vis the drives and sensibilities of the body and brain, residual past consciousnesses of recycled subatomic particles, and through the deferment of meaning in ego-centered communicative discourse are given free rein to reproduce their practices within the social system, which is grounded in the reproduction and differentiation of the social relations of production. On the contrary, their practices are relationally constrained within the structure and differentiation of the system or social structure as determined by class division and the social relations of production through, contemporarily, bourgeois/underclass bodies, mode of production, language, ideologies, ideological apparatuses, and communicative discourse, dialectically, seeking equality of opportunity, recognition, and distribution for these once discriminated against alternative practices within the social class language game of the postindustrial bourgeois state. In essence, by accounting for both structural reproduction and differentiation and social practices arriving through the deferment of meaning in ego-centered communicative discourse, Habermas is highlighting the power dynamics or mechanical solidarity of postindustrial capitalist society, which marginalizes against previous discriminatory practices, i.e., sexism, patriarchy, racism, and homophobia, for its post-racial, post-sexual, etc. constitution where the bourgeoisies of oncediscriminated against subjective positions marginalize and discriminate against the underclasses of their communities. In a word, Habermas overlooks, by labeling the phenomenon "a crisis," the power relations by which postindustrial (Protestant/Capitalist) society, even Durkheim's mechanical solidarity, is constituted in favor of the bourgeoisies, which have internalized the practical consciousness of the social structure, of once discriminated against subjective positions.

In sum, the structurationist or praxis school in the social sciences is commonly associated with Jürgen Habermas [16-18], Pierre Bourdieu [9-11], and Anthony Giddens [15] in sociology, and Marshall Sahlins [12-14] in anthropology [8, 7]. Elaborated in a series of theoretical works and empirical studies, structurationists or praxis theorists account for agency and consciousness in social structure or system, "by clamping action and structure together in a notion of 'practice' or 'practises"' [8]. That is, structures are not only external to social actors, as in the classic structural functional view, but are also internal rules and resources produced and reproduced by actors "unconsciously" (intuitively) in their practices. In structurationist or praxis theory, as Marx one-hundred years before suggested, the structure is "not a substantially separable order of reality", but "simply the 'ideal' form in which the totality of 'material' relations...are manifested to consciousness..." [23]. From this perspective, accordingly, structure or, sociological speaking, social structure, "may set [(ideological)] conditions to the historical process, but it is dissolved and reformulated in material practice [(through mode of production and ideological apparatuses)], so that history becomes the realization, in the form of society, of the actual [(embodied rules)] resources people put into play" $[13,14]$ : consciousness, as a result, refers to "practical consciousness" or the dissolution and reformulation of a social structure's terms (norms, values, prescriptions, and proscriptions) in material practice.

Although this Neo-Marxist "clamping together" of structure, praxis, and consciousness descriptively accounts for "the individual moment of phenomenology" by explaining the unanimity, closure, and "intentionality" of a form of human action or sociation, the capitalist social (material) relations of production and its class divisions and differentiations, which constitute the integrative actions of modern society. It fails, however, as pointed out in the epistemological postmodern/post-structural positions of Michel Foucault, Jacques Derrida, Jacques Lacan, bell hooks, and Patricia Hill-Collins, to account for the origins and nature of fully visible alternative forms of practices (i.e., "the variability of the individual moments of phenomenology") within the dominant order that are not class based, but are the product of the deferment of meaning in ego-centered communicative discourse, a la the Vodou Ethic and the spirit of communism social class language game of the Vodou leadership of Haiti, for example. Structurationists fail to see that society and its dominant institutionalized identity and behavior are not solely "one-dimensional," i.e., a duality, and differentiated by the dialectic of capitalist social relations of production, but is constituted, through power relations, as transition, relation, and difference. This difference, akin to Jacques Derrida's différance, is not biologically (racially) hardwired in the social actor. It is a result of selfreflective and non-impulsive social actors, upon internalizing the arbitrary structural terms or signifiers of their society via their consciousness, bodies, language, and linguistic communication, conceiving of and exercising other forms of being-in-the-world from that of the dominant symbolic order and its structural differentiation or relational logic through the deferment of meaning in ego-centered communicative discourse [16- 18, 15].

By "clamping" action, structure, and consciousness together, i.e., part/whole totality, however, structurationists do not account for, nor demonstrate, the nature and relation of this non- 
Paul C. Mocombe., J Adv Educ Philos, Feb, 2021; 5(2): 32-51

biologically and non-impulsive determined difference (differance) to that of the dominant practices of the social structure as highlighted in the theorizing of postmodern and post-structural scholars. Instead, they re-introduce the problem in a new form: How do we know or exercise anything at odds with an embodied received view grounded in, and differentiated by, capitalist social relations of production? Paul C. Mocombe's [24, 21, 25, 20, 26, 27] phenomenological structural ontology/sociology, phenomenological structuralism, seeks to fix structurationism to account for this problematic by synthesizing Haitian epistemology, i.e., Haitian/Vilokan idealism, the materialism of physics, with the agential initiatives highlighted in the phenomenological method and discourses of Haitian/Vilokan idealism, Husserl, Heidegger, Merleau-Ponty, and Sartre, the Neo-Marxist structuralism of Althusser and structurationism, and Wittgenstein's notion of language game.

For Mocombe, in building on the duality concept of structuration theory, human social action, consciousness, and identity is not only a duality determined by their relation to the mode of production and its differentiation. But, in building on the work of Margaret Archer [19] in her critique of structurationism, it is also a dualism. Not a conceptual dualism as Archer points out, but a reified external one, the externalized structure of a society reified, in the words of Louis Althusser [6, 5], through language, ideology, ideological apparatuses, communicative discourse, and the mode of production. As such, social action and identity/consciousness constitution are not necessarily a duality, i.e., the internalization of the external language, ideology, etc., of a social structure recursively (re) organized and reproduced as the practical consciousness of a social actor. Duality is a contingent phenomenon based on a human subject's stance/analytics (mental/cognitive state) vis-à-vis the reified structure, which presupposes their existence and the will of those in power positions. In other words, alternative actions or practical consciousnesses are distinct reified languages, ideologies, ideological apparatuses, communicative discourses, and modes of production from that of the dominant social structure within which they operate. These alternative actions or practical consciousnesses are the product of four sources, and Being's stance, ready-to-hand, unready-tohand, and present-at-hand, vis-à-vis them: 1) the drives of the body and brain, 2) impulses of residual actions/memories (phenomenal properties) of embodied recycled/entangled/superimposed past/present/future consciousnesses of subatomic particles, psychions 3) ideologies of a social system along with its differentiating logic (structural reproduction and differentiation), which produces the variability of actions and practices in cultures, social structures, or social systems as highlighted by structurationist theorists, and 4) the "present-at-hand" phenomenological meditation/deferment that occurs on the latter actions via linguistic/symbolic communication. The exercise of power by social actors in power positions in the ideological apparatuses social actors are interpellated and subjectified in, in the end, determines what practical consciousnesses are allowed to manifest in a material resource framework without a social actor facing alienation, marginalization, or death. Hence structural reproduction and differentiation for Mocombe is always a product of power and power positions in relation to a social actor's stance or analytic.

To this end of fixing structurationism to account for the nature and origins of alternative practical consciousnesses outside the structural reproduction and differentiation of capitalist relations of production, Paul C. Mocombe's [21, 25, 20] phenomenological structuralism builds on Haitian/Vilokan idealism and the material relationship highlighted in physics between the identity and indeterminate behavior of subatomic particles highlighted in quantum mechanics and the determinate behavior of atomic particles in their aggregation as highlighted in general relativity to understand the material constitution of consciousness at the subatomic/neuronal level in, and as, the brain and its manifestation as human practical consciousness at the atomic level as revealed by modes of production, language, ideologies, ideological apparatuses, communicative discourse, and the actions of the body in multiple worlds.

\section{Theory \\ Introduction to Phenomenological Structuralism}

Against dualism and idealism Paul C. Mocombe's [20, 22, 26] philosophy and structurationist sociology, phenomenological structuralism, which attempts to resolve the structure/agency problematic of the social sciences, is a logico-metaphysical materialist philosophy, which posits that we live in a material multiverse composed of brute facts, which human consciousness reifies as ideas, concepts, and theories via language and the abstractions of space/time geometry and mathematics (Mocombeian nominalism). For Mocombe [20, 22, 26], quantum superposition, entanglement, wave-function realism, and evidence in Haitian Vodou of psychic phenomena and spirit possession, which represent ancestors from a parallel world, Vilokan, of the earth's of which we ought to pattern our behaviors and structures, are grounding proofs for the acceptance of the multiple worlds hypothesis of quantum mechanics. Within the latter hypothesis, the understanding is that "each possibility in a superposition evolves to form its own universe, resulting in an infinite multitude of [(replicated)] coexisting 'parallel' worlds. The stream of consciousness of the observer is supposed somehow to 'split', so that there is one in each of the worlds-at least in those worlds for which the observer remains alive and conscious. Each instance of the observer's 
Paul C. Mocombe., J Adv Educ Philos, Feb, 2021; 5(2): 32-51

consciousness experiences a separate independent world, and is not directly aware of any of the other worlds" [28]. It is within this multiple world hypothesis, physics, that Mocombe constitutes his understanding of the emergence of the material multiverse and the notion of consciousness in each of the universes according to his theory of phenomenological structuralism. For Mocombe, consciousness, like the material multiverse, is emergent; an emergent fifth force of nature, a field of consciousness/consciousness field, composed of a quantum material substance/energy, psychion (which constitutes a "field of consciousness), the phenomenal properties, qualia, of which are recycled/replicated/entangled/superimposed throughout the multiverse and becomes embodied via the microtubules of neurons of brains and their electromagnetic fields (which holds together and integrates consciousness). It (consciousness) is manifested in simultaneous, entangled, superimposed, and interconnecting material resource frameworks as mind or embodied praxis or practical consciousness, which in-turn becomes the phenomenal properties, qualia, of material (subatomic particle energy, psychion) consciousness that is recycled/entangled/superimposed throughout the multiverses following matter disaggregation. In other words, existence precedes essence; but essence is emergent and eternal, and comes to constitute a fifth force of nature, a field of consciousness/consciousness field for Being production, through the phenomenal properties, qualia, of neuronal subatomic particles, psychions, which are recycled/replicated/superimposed/entangled throughout the multiverse and give human actors their initial (essential) practical consciousness.

To formulate the basic premise of this metaphysics, I adopt from the "membrane theory" model of Lisa Randall and Raman Sundrum [29] the assertion, in keeping with the logic of Haitian Vodou, that there might be an additional dimension on the cosmological scale, the scale described by general relativity, which gives rise to four dimensional multiverses within it. That is to say, our universe is embedded in a vastly bigger five-dimensional space (the four-dimensional space of relativity, plus a fifth dimension for the subatomic forces including consciousness), a kind of super-universe. Within this super-space, our universe is just one of a whole array of co-existing universes (Haitian Vodou only accounts for our universe and its parallel), each a separate fourdimensional bubble within a wider arena of fivedimensional space where consciousness (a subatomic force) is recycled/replicated/entangled/superimposed between the phenomenal properties/informational contents of the species of the five-dimensional superspace, i.e., superverses, and their four-dimensional multiverses (see Figure-3).
The origins of consciousness and the multiverse within this phenomenal structural paradigm is material and emergent, and not the product of a supreme creator or god. For this position, I build on the mathematics of Richard Gauthier [30] in his "univon multiverse hypothesis." Unlike Gauthier, who holds on to God or a supreme creator to account for the origins and nature of consciousness within the multiverse, I do not. According to Gauthier's [30] model, identical univon quantum particles, produced from a univon quantum field, created not only our universe but also many other identically fine-tuned universes in a multiverse. The univon, also called a cosmic quantum, is composed of a helically-circulating superluminal primordial information quantum (sprinq). [(The univon is the quantum particle of a conscious cosmic quantum field having both physical and mental potentialities. Quantum fields may be composed of cosmic ectoplasm or mind-stuff, which according to yoga philosophy is a subtle vibrational substance formed from consciousness by a cosmic creative power, that takes the form of objects within a cosmic mind)]. The physical [(and mind-stuff)] constants carried in the information content of each univon's sprinq are exactly the same in all univons and in all sprinqs, though sprinqs express different fundamental particle attributes in different environments. The univon is radioactive. The decay of a univon into less energetic products is the starting point $(\mathrm{t}=0)$ of its created universe. The univon's sprinq rapidly multiplies itself into different quantum fields and particles, leading very quickly to the early universe's exponentially-rapid inflationary period and then to the Big Bang, which produces abundant relic dark matter particles of the universe as well as the less abundant ordinary matter. Univons made many other [(entangling)] equally fine-tuned universes with identical fundamental forces and constants.... (pgs. 13).

In my metaphysical materialistic model, which differs in language and the need for a "cosmic mind," the "univon" is the cosmological scale described by Einstein constituted by the forces, constants, particles, etc., sprinqs in Gauthier's hypothesis and phenomenal properties or qualia in my model, of the multiverses, with gravity and the psychionic force of consciousness emergent forces following matter aggregation, evolution, and disaggregation, which give rise to inflation, big bangs, and additional (entangled) universes with similar (replicated) informational (physical and mental) content. Hence, the mathematics for both models are the same as seen in Figures 1 and 2, which is adopted from Gauthier [30].

I tie this physical model to Black Hole Big Bang Theory (BHBBT) - the understanding "that matter from a mother universe collapses into a black hole. The singularity of this black hole is at a single point in space with respect to anyone in the mother universe. But, because of the reversal of time and space 
Paul C. Mocombe., J Adv Educ Philos, Feb, 2021; 5(2): 32-51

for anyone inside the daughter universe, that point in space $r=0$ become their initial point in time, $t=0$. Hence, what was a singularity in space is now a singularity in time, just like the Big Bang. This means that any matter falling in from the mother universe will disappear from that universe and emerge at the initial $\mathrm{t}=0$ point of the daughter universe thoroughly scrambled. Not only that, but what emerges at the Big Bang is not just the matter that was there at the black hole's formation but all matter that ever fell into it [31]." Mocombe's structuration theory, phenomenological structuralism, to explain the emergence and constitution of the multiverses, consciousness, minds, and society in them (see Figure-3).

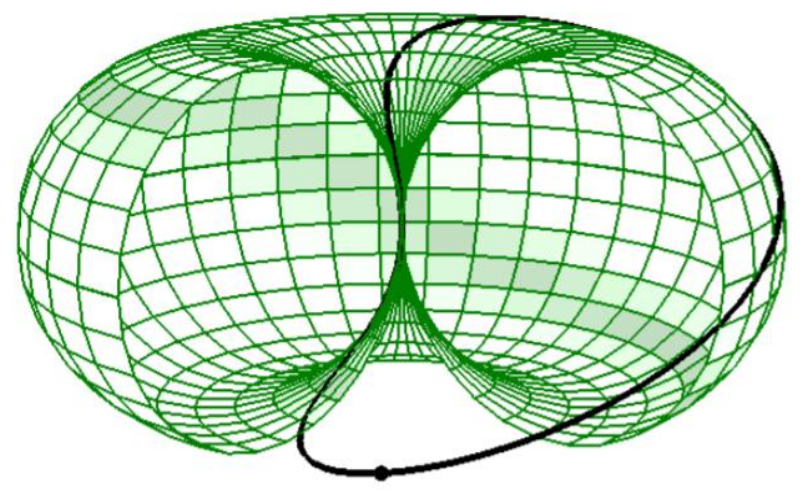

Fig. 1. The univon model composed of a superluminal primordial information quantum (sprinq). The mathematical horn torus surface on which the spring travels is cut away to show the interior. The black closed curve on the surface of the horn torus is the trajectory of the univon's sprinq (indicated by the black dot.)

$$
\begin{gathered}
x(t)=R(1+\cos (\omega t)) \cos (\omega t) \\
y(t)=R(1+\cos (\omega t)) \sin (\omega t) \\
z(t)=R \sin (\omega t) \\
R=\hbar / M c=2.9 \times 10^{-97} \mathrm{~m} \\
\omega=M c^{2} / \hbar=1.0 \times 10^{105} \text { radians } / \mathrm{s} \\
M=\text { mass of observable universe }=1.2 \times 10^{54} \mathrm{~kg}
\end{gathered}
$$
Fig. 2. The parametric equations of the univon model composed of a circulating sprinq. The calculated maximum
speed of the circulating qprinq is $c \sqrt{5}=2.236 c$ (at the equator of the mathematical torus) while its minimum speed
is $c$ (at the center of the mathematical torus).

\section{Structurationism and Phenomenological Structuralism}

To the aforementioned physical and metaphysical processes (the brute fact that we are a product of a multiverse that has always existed, which is entangled, superimposed, and replicated via black holes), I add the biology and psychology of embodiment to the sociology of structuration theory to account for the emergence of human action and its relation to consciousness in the determinism of the multiverses, the constitution of societies, and individuation. Structurationist sociology, as previously highlighted, synthesizes structure and agency via the concept of praxis or practical consciousness; accounting for human agency or practical consciousness via the actions associated with (societal) structural reproduction and differentiation within a particular material resource framework [8, 7]. This latter factor, however, does not account for the moments or movements, which escape from the compound of socially constructed identifications, which for Mocombe is epiphenomenal. Building on structurationist sociology in relation to the physics and metaphysics of phenomenological structuralism, Mocombe argues that the "moments, or movements, which escape from the compound of socially constructed identifications" are the product of an individual actors' (mental) stance/analytics (Martin Heidegger's term) vis-à-vis three types of structures/systems of signification amidst the practical consciousness associated with societal structural reproduction and differentiation (the social system), which is a tertiary process: 1) the (chemical, biological, and physiological) drives (forms of sensibility and understanding) of the body and brain (the biological system), 2) impulses or phenomenal properties of residual past/present/future consciousnesses or recycled/replicated/entangled/superimposed subatomic/chemical particles, psychions, encapsulated in and as the neuronal energies and qualia of the brain 
Paul C. Mocombe., J Adv Educ Philos, Feb, 2021; 5(2): 32-51

via microtubules of neurons and their EM field (the physical system), 3) and actions or practical consciousnesses resulting from the deferment of meaning in ego-centered linguistic and symbolic communicative discourse (the linguistic system). Our ability to perform the latter, defer meaning in egocentered communicative discourse, is what gives us as a species the illusion of choice and free-will amidst the aforementioned determining structures the second of which is tied to our connection to the (physical) multiverse and its constitution.

Generally speaking, consciousnesses, actions (practical consciousness), learning, and development within Mocombe's phenomenological structural ontology are the product of the embodiment of the phenomenal properties, qualia, of recycled/replicated/entangled/superimposed subatomic neuronal energies/chemicals, psychion, of the multiverse objectified in the space-time of multiverses via the aggregated body and the microtubules of neurons of the brain (see Figure-4). A Consciousness field produces consciousness, which is embodied in microtubules of neurons of the brain and held together and integrated by its electromagnetic field. The consciousness field is an emergent fifth force of nature composed of the psychion, which is the energy substance/force that constitutes the ego essence of an individual person. The ego essence, psychion, is composed of all of the personal and collective sense experiences (personal and collective unconscious of the ego), the phenomenal properties or qualia, of the individual person, which becomes embodied as a result of matter aggregation across multiple simultaneous existing past/present/future worlds/universes. The structure of the mind, in the end, is composed of the ego and the personal and collective unconscious, which becomes embodied, as the qualia of psychions, via the microtubules of neurons of the aggregated brain and its EM field across replicated simultaneous past/present/future worlds of the multiverse (see Figure4). The EM field's "source is the electrical dipoles within the neuronal membranes caused by the motion of ions in and out of those membranes during action potentials and synaptic potentials. The periodic discharge of neurons - firing or action potentialsgenerates EMF waves that propagate out of the neuron and into the surrounding inter-neuronal spaces where they overlap and combine to generate the brain's global EM field that is routinely measured by brain scanning techniques such as electroencephalography (EEG) and magnetoencephalography (MEG)" [32]. The EM field holds together, like a glue, the ego essence, individuated consciousness of being, their psychion, which emerges out of its own force, the consciousness field. The ego, in other words, is the (material) essence, psychion, of the individual being. It is a composite of their past/present/future experiences, which emerge as the personal and collective unconscious, i.e., qualia, of the ego. The latter two as such are the past/present/future biological and sociological sense experiences of the ego over all of its lived-experiences across the multiverse. Once objectified and embodied the phenomenal properties, qualia, of the neuronal energies/chemicals, psychion, encounter the space-time of physical worlds via a transcendental subject of consciousnesses (the aggregation of a universal-self replicated, superimposed, and entangled across the multiple worlds of the multiverse) and the drives and sensibilities of the aggregated body and brain in reified structures of signification, language, ideology, ideological apparatuses, and communicative discourse defined and determined by other beings that control the resources (economics), and modes of distributing them, of the material world required for physical survival in space-time. The Heideggerian (mental) stances/analytics, "ready-to-hand," "unready-to-hand," and "present-at-hand," which emerge as a result of conflict (or lack thereof) between the embodied transcendental ego (qualia) vis-à-vis its different (structuring) systems, 1) the sensibilities and (chemical, biological, and physiological) drives of the body and brain, 2) drives/impulses of embodied residual memories or phenomenal properties of past/present/future recycled/entangled/superimposed subatomic/chemical particles, 3) the actions produced via the body in relation to the indeterminacy/deferment of meaning of linguistic and symbolic signifiers as they appear to individuated consciousnesses in ego-centered communicative discourse, 4) and the dialectical and differentiating effects, i.e., structural reproduction and differentiation, of the structures of signification, social class language game, of those who control the economic materials (and their distribution, i.e., mode of production) of a world are the origins of practical consciousnesses. All four types of actions, the drives and sensibilities of the body and brain, drives or phenomenal properties of embodied recycled/replicated/entangled/superimposed

past/present/future consciousnesses, structural reproduction/differentiation stemming from the mode of production, and deferential actions arising from the deferment of meaning in ego-centered communicative discourse via the present-at-hand stance/analytic, exist in the material world with the social class language game, i.e., the physical, mental, emotional, ideological, etc. 5) powers of those who control the material resource framework as the causative agent for individual behaviors. In other words, our (mental) stances in consciousness vis-à-vis the conflict (or lack thereof) between the (chemical, biological, and physiological) drives and sensibilities of the body and brain, (societal) structural reproduction and differentiation, drives of embodied past/present/future consciousnesses of recycled/entangled/superimposed subatomic/chemical particles, and deferential actions arising as a result of the deferment of meaning in egocentered communicative discourse determines the practical consciousness we want to recursively reorganize and reproduce in the material world. The 
Paul C. Mocombe., J Adv Educ Philos, Feb, 2021; 5(2): 32-51

power, power positions, and power relations of those who control (via the mode of production, language, ideology, ideological apparatuses, and communicative discourse) the resources (and their distribution, i.e., mode of production) of a material resource framework, and the threat it poses to the ontological security of an actor, in the end determines what actions and identities are allowed to organize and reproduce in the material world without the individual actor/agent facing marginalization or death.

It is Being's (mental) stance/analytic, "readyto-hand," "unready-to-hand," and "present-at-hand," in consciousness vis-à-vis the conflict, or lack thereof, between the (chemical, biological, and physiological) drives and sensibilities of the aggregated body and brain, drives/impulses (phenomenal properties) of residual past/present/future consciousnesses of recycled/replicated/entangled/superimposed subatomic particles, alternative practices which arise as a result of phenomenological meditation and deferment of meaning, along with the differentiating logic or class divisions of the social relations of production, which produces the variability of actions and practices in cultures, social structures, or social systems and gives us the illusion of free-will. All four types of actions are always present and manifested in a social structure to some degree contingent upon the will and desires of the economic social class, power elites, which controls the material resource framework through its body (practical consciousness), language/symbols, ideology, ideological apparatuses, and social relations of production. They choose, amidst the class division of the social relations of production, what other meaning constitutions and practices manifest themselves in the material world without facing alienation, marginalization, domination, or death.

Hence, we never experience the things-inthemselves of the world culturally and historically in consciousness. We experience them structurally or relationally, the structure of the conjuncture of the mode of production, its language, ideology, ideological apparatuses, etc., and our (mental) stances/analytics, ready-to-hand, unready-to-hand, present-at-hand, vis-àvis these things as they appear to and in consciousness determine our practical consciousness or behaviors.

We initially know, experience, and utilize the things of and in consciousness in the preontological ready-to-hand mode, which is structural and relational. That is, our bodies encounter, know, experience, and utilize the things of the world in consciousness, intersubjectively, via their representation as objects of knowledge, truth, usage, and experience enframed and defined in the relational logic and practices or language game (Wittgenstein's term) of the institutions or ideological apparatuses of the other beings-of-thematerial resource framework whose historicity comes before our own and gets reified in and as the actions of their bodies, language, ideology, ideological apparatuses, mode of production, and communicative discourse. This is the predefined phenomenal structural, i.e., ontological, world we and our bodies are thrown-in in coming to be-in-the-world. How an embodiedhermeneutically-structured Being as such solipsistically view, experience, understand, act, and utilize the predefined objects of knowledge, truth, and experienced defined by others and their conditions of possibilities in consciousness in order to formulate their practical consciousness is albeit indeterminate. Martin Heidegger in Being in Time is accurate, however, in suggesting that three stances or modes of encounter (Analytic of Dasein), "presence-at-hand," "readiness-to-hand," and "un-readiness-to-hand," characterizes our views of the things of consciousness represented intersubjectively via bodies, language, ideology, and communicative discourse, and subsequently determine our practical consciousness or social agency. In "ready-to-hand," which is the preontological mode of human existence thrown in the world, we accept and use the things in consciousness with no conscious experience of them, i.e., without thinking about them or giving them any meaning or signification outside of their intended usage. Heidegger's example is that of using a hammer in hammering. We use a hammer without thinking about it or giving it any other condition of possibility outside of its intended usage as defined by those whose historicity presupposes our own. In "present-at-hand," which, according to Heidegger, is the stance of science, we objectify the things of consciousness and attempt to determine and reify their meanings, usage, and conditions of possibilities as the nature of reality as such. Hence the hammer is intended for hammering by those who created it as a thing solely meant as such. The "unready-to-hand" outlook is assumed when something goes wrong in our usage of a thing of consciousness as defined and determined by those who adopt a "present-at-hand" view. As in the case of the hammer, the unready-to-hand view is assumed when the hammer breaks and we must objectify it, by then assuming a present-at-hand position, and think about it in order to either reconstitute it as a hammer, or give it another condition of possibility. Any other condition of possibility that we give the hammer outside of its initial condition of possibility which presupposed our historicity becomes relational, defined in relation to any of its other conditions of possibilities it may have been given by others we exist in the world with who either ready-to-hand, unready-to-hand, or present-at-hand attempts to maintain the social class language game of power. In the ready-to-hand stance the latter unconsciously practices and attempts to reproduce the social class language game of power by discriminating against and marginalizing any other conditions of possibilities of their social class language as determined by those in ideological power positions. They may move to the unready-to-hand stance in response to those who they encounter that attempts, present-at-hand, to alter the nature of the dominant social class language 
game they recursively reorganize and reproduce as outlined by those in power positions who are present-athand of the dominant social class language game. In either case, not all beings achieve the present-at-hand stance. The latter is the stance of science and ideologies, which are tautologies when they profess that their stances represent the nature of reality as such, and those in power positions, who choose, among a plethora of alternative present-at-hand social class language games, what alternative practical consciousnesses outside of their social class language game that are allowed to manifest in the material world.

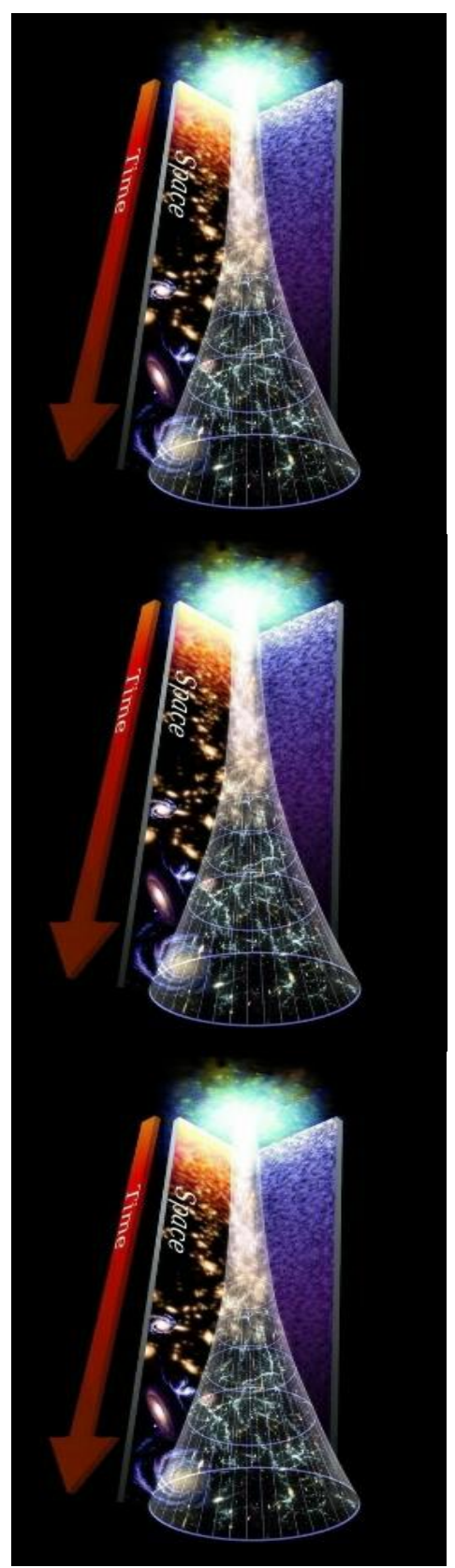

Fig-3

Figure-3 For Mocombe, building on BBBHT, the superverses with entangled and superimposed (via black holes) multiverses share the same informational content. So, the hypothesis here is that one superverse created a universe, and its informational content is entangled and superimposed on top of another superverse with the informational content of the previous universe emerging in it via black holes. Hence what you have is a layer of multiverses and superverses, superimposed and entangled, whose informational content is shared or recycled via black holes, which organize and structure the multiverses similarly. As such, quantum fluctuation and big bangs are constantly occurring and producing the same worlds, ad infinitum. So, when physicists look out to the cosmic microwave background (CMB), they are looking at the remnant from an early stage of our universe, which came forth from its older version a layer above it, and so on ad infinitum. Put more concretely, the physicists are in a superverse, of our universe, in our milky-way galaxy, looking out to the black hole of a milky-way galaxy from the superverse/multiverse above us.

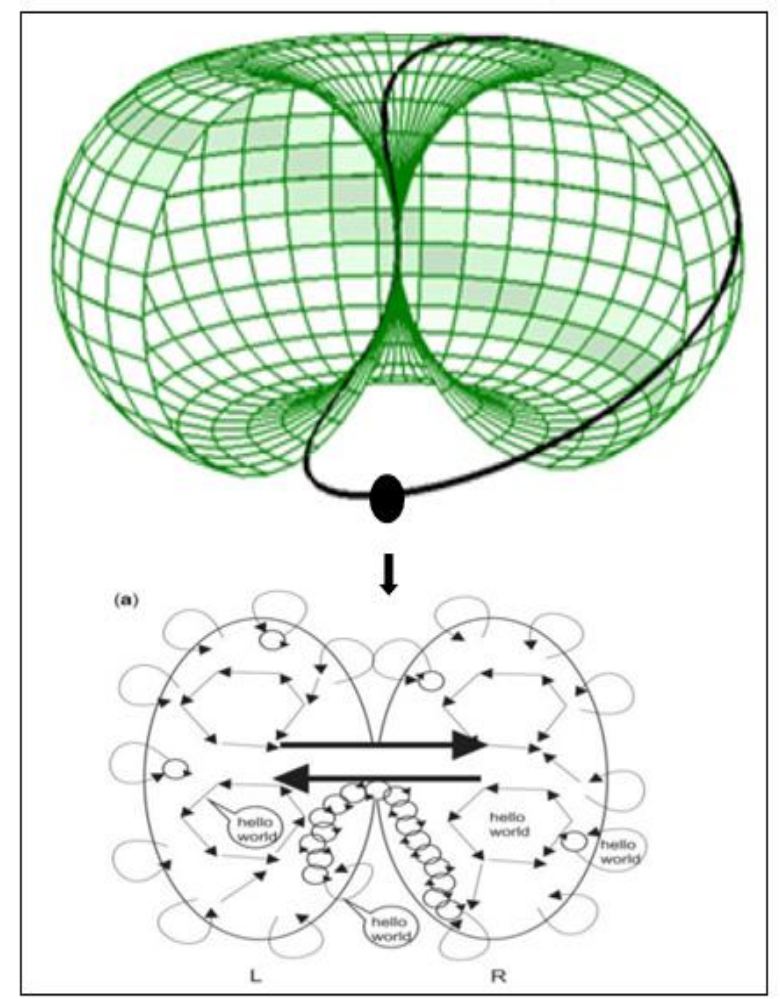

Fig-4

Figure-4 This figure represents how the psychions are embodied from the consciousness field (CF) in the microtubules of neurons of brains (figure a, adopted from McFadden, 2020, represents the human brain - left (L) and right (R) hemispheres - and its EM field, which holds together and integrates the qualia of psychions, informational content of the superverse/multiverses, which becomes individuated consciousness recursively organized and reproduced as practical consciousness), which produces an EM field that holds together and integrates the qualia of the psychions as individuated consciousness. For Mocombe, building on BBBHT, the superverses with entangled and superimposed (via black holes) 
Paul C. Mocombe., J Adv Educ Philos, Feb, 2021; 5(2): 32-51

multiverses share the same informational content. So, the hypothesis here is that one superverse created a universe, and its informational content is entangled and superimposed on top of another superverse with the informational content of the previous universe emerging in it via black holes. Hence what you have are a layer of multiverses and superverses, superimposed and entangled, whose informational contents are shared or recycled via black holes, which organize and structure the multiverses similarly. As such, quantum fluctuation and big bangs are constantly occurring and producing the same worlds, ad infinitum. The informational content, qualia, of these multiverses and worlds are encoded and transmitted as psychions and embodied in the microtubules of neurons of brains, which create an EM field that holds and integrates the psychions as individuated consciousness.

\section{The Evolution of Consciousness, Individual Psychology, and Mind within Phenomenological Structuralism}

Hence, as outlined above, phenomenological structuralism posits consciousness to be the by-product or evolution of subatomic particles, psychion, with phenomenal properties, qualia, unfolding (out of an emergent consciousness field) with increasing levels of abstraction within entangled, replicated, and superimposed material resource frameworks enframed by the mode of production, language, ideology, ideological apparatuses, and communicative discourse (i.e., social class language game) of bodies recursively reorganizing and reproducing the ideals of the latter factors as their practical consciousness. Our universe is embedded in a vastly bigger five-dimensional space (the four-dimensional space of relativity, plus a fifth dimension for the subatomic forces including consciousness), a kind of super-universe. Within this super-space, our universe is just one of a whole array of co-existing, entangled, and superimposed universes (Haitian Vodou only accounts for our universe and its parallel), each a separate four-dimensional bubble, which share the same informational contents via black holes (BHBBT), within a wider arena of fivedimensional space where consciousness (a subatomic force, i.e., psychion, and its phenomenal properties, qualia) emerges and is recycled/replicated/entangled/superimposed between the five-dimensional super-space, i.e., superverses, and their multiverses.

For Mocombe the multiverses originated, from the super-universes, either by fiat or quantum fluctuation. They are bosonic forces that were brought forth together with fermion counterparts. They are also the primeval pan-psychic fields, stemming from the superimposed and entangled super-verses, whose fermion can be called a psychion, a particle of consciousness or proto-consciousness. These have evolved together with the four forces of nature, electromagnetic force; gravity; the strong nuclear force; and weak nuclear force, in our universe, which in turn produced atoms, molecules, and aggregated life endowed (embodied) with the recycled/replicated/entangled/superimposed

consciousness and phenomenal properties, qualia or informational content, of the primeval pan-psychic fields, psychion (the fifth force of nature), of the superverses and their multiverses. In other words, the superverses with entangled and superimposed (via black holes) multiverses share the same informational content. So, the hypothesis here is that one (original) superverse created a universe, and its informational content is entangled and superimposed on top of another superverse with the informational content of the previous universe emerging and replicating in it via black holes. Hence, what you have are layers of multiverses and superverses, superimposed and entangled, whose informational contents are shared or recycled and replicated via black holes, which organize and structure the multiverses similarly. As such, the basic idea for this Black Hole Big Bang Theory (BHBBT) is that quantum fluctuation and big bangs are constantly occurring and producing the same worlds, superimposed and entangled, ad infinitum. So, when physicists look out to the cosmic microwave background (CMB), they are looking at the remnant from an early stage of our universe, which came forth from its older version a layer above it, and so on ad infinitum (see Figure 3). Put more concretely, the physicists are in a superverse, of our universe, in our milky-way galaxy, looking out to the black hole of a milky-way galaxy from the superverse/multiverse above us.

Within these same worlds or multiverses, subatomic particles, via the Higgs boson particle, give/gave rise to carbon atoms, molecules and chemistry, which give/gave rise to DNA, biological organisms, neurons and nervous systems, which aggregate/aggregated into bodies and brains that give/gave rise to the embodiment of preexisting consciousness of the subatomic particles, bodies, and languages from entangled/superimposed multiverses. In human beings, the indeterminate behavior of superimposed, entangled, and replicated subatomic neuronal energies that produced the plethora of consciousnesses and languages in the neocortex of brains gave rise to ideologies, which in turn gave rise to ideological apparatuses and societies (sociology) under the social class language game or language, ideology, and ideological apparatuses of those who organize and control the material resources (and their distribution) required for physical (embodied) survival in a particular resource framework. In other words, existence precedes essence; but essence is emergent and eternal, and comes to constitute a fifth force of nature, a field of consciousness/consciousness field for Being production, through the phenomenal properties, qualia, of neuronal subatomic particles, psychions, which are recycled/replicated/superimposed/entangled throughout 
Paul C. Mocombe., J Adv Educ Philos, Feb, 2021; 5(2): 32-51

the multiverse and give human actors their initial (essential) practical consciousness among the structuring structure of the drives of the biological body, a social structure or social class language game, and the ability to defer meaning in ego-centered communicative discourse (see Figure-4).

So contrary to Karl Marx's materialism which posits human consciousness to be the product of material conditions, the logic here is a structural Marxist one in the Althusserian sense. That is, the aggregated, atomic, mature human being is a body and neuronal drives that never encounters the (ontological) material world directly. Instead, they encounter the (ideological) world via structures of signification, which structures the world or a particular part of it through the body, language, ideology, ideological apparatuses, and communicative discourse, i.e., social class language game, of those whose power, power positions, and power relations dictate how the resources of that framework are to be gathered, used, and distributed (means and mode of production).

Hence in the end, societal and subject constitution, mind organizing and reproducing consciousness as praxis, is a product of conflict and an individual's mental stance, i.e., analytics, vis-à-vis three structures/systems of signification and the ability to defer meaning in ego-centered communicative discourse stemming from the social class language game (i.e., language, symbols, ideology, ideological apparatuses, and communicative discourse) of those who control the mode of production of a material resource framework. It is the ready-to-hand drives of the body and brain, ready-to-hand and present-at-hand manifestation of past/present/future recycled residual consciousnesses/subatomic particles, the present-athand phenomenological meditation and deferment of meaning that occurs in embodied consciousness via language, ideology, and communicative discourse as reflected in diverse individual practices, within the ready-to-hand, unready-to-hand, and present-at-hand differentiating logic or class divisions of the social relations of production, which produces the variability of actions and practices in cultures, social structures, or social systems. All four types of actions, the (chemical, biological, and physiological) drives/impulses of the body and residual past consciousnesses of subatomic particles, structural reproduction/differentiation, and actions resulting from the deferment of meaning in egocentered communicative discourse, are always present and manifested in a social structure (which is the reified ideology via ideological apparatuses, their social class language game, of those who control a material resource framework) to some degree contingent upon the will and desires of the economic social class that controls the material resource framework through the actions of their bodies (practical consciousness), language, symbols, ideology, ideological apparatuses, and social relations of production. They choose, amidst the class division of the social relations of production, "the structure of the conjuncture," (Marshall Sahlins's term) what other meaning constitutions and practices are allowed to manifest themselves without the Beings of that practice facing alienation, marginalization, domination, or death.

The individual being is initially constituted as superimposed, entangled, recycled, and embodied subatomic particles, psychion, of multiple worlds of the multiverse, which have their own predetermined form of understanding and cognition, phenomenal properties, qualia, based on previous or simultaneous experiences as aggregated matter (this is akin to what the Greek philosopher Plato refers to when he posits knowledge as recollection of the Soul; and Nietzsche's idea of eternal recurrence). Again, the individual's actions are not necessarily determined by the embodiment and drives of these recycled (replicated)/entangled/superimposed subatomic particles. It is conflict and an individual's stance, ready-to-hand, unready-to-hand, and present-athand, when the subatomic particles become aggregated matter or embodied, which determines whether are not they become aware, present-at-hand (third person position), of the subatomic particle drives and choose to recursively reorganize and reproduce the content of the drives as their practical consciousness.

This desire to reproduce the cognition and understanding of the (chemical, biological, and physiological) drives of the recycled/replicated/entangled/superimposed subatomic particles, however, may be limited by the structuring structure of the aggregated body and brain of the individual subject. That is to say, the second origins and basis of an individual's actions are the structuring drives and desires, for food, clothing, shelter, social interaction, and sex, of the aggregated body and brain, which the subatomic particles constitute and embody. In other words, the aggregated body and brain is preprogrammed with its own (biological, chemical, and physiological) forms of sensibility, understanding, and cognition, structuring structure, by which it experiences being-in-the-world as aggregated embodied subatomic particles. These bodily forms of sensibility, understanding, and cognition, such as the drive and desire for food, clothing, shelter, social interaction, linguistic communication, and sex, are tied to the material embodiment and survival of the embodied individual actor, and may or may not supersede or conflict with the desire and drive of an individual to recursively (re) organize and reproduce the structuring structure of the superimposed, entangled, and recycled (phenomenal properties of) subatomic particles. If these two initial structuring structures are in conflict, the individual moves from the ready-to-hand to the unready-to-hand stance or analytics where they may begin to reflect upon and question their being-in-theworld prior to acting. Hence just as in the case of the structuring structure of the subatomic particles it is an 
Paul C. Mocombe., J Adv Educ Philos, Feb, 2021; 5(2): 32-51

individual being's analytics vis-à-vis the drives of its body and brain in relation to the impulses of the subatomic particles, which determines whether or not they become driven by the desire to solely fulfill the material needs of their body and brain at the expense of the drives/desires of the subatomic particles or the social class language game of the material resource framework they find their existence unfolding in.

The social class language game, and its differentiating effects, an individual find their existence unfolding in is the third structuring structure, which attempts to determine the actions of individual beings as they experience being-in-the-world as embodied subatomic particles. The aggregated individual finds themselves objectified and unfolding within a material resource framework controlled by the actions of other bodies, which presuppose their existence, via the actions of their bodies (practical consciousness), language, communicative discourse, ideology, and ideological apparatuses stemming from how they satisfy the desires of their bodies and subatomic particle drives (means and mode of production). What is aggregated as a social class language game by those in power positions via and within its mode of production, language, ideology, ideological apparatuses, and communicative discourse attempts to interpellate and subjectify other beings to its interpretive frame of satisfying their bodily needs, fulfilling the impulses of their subatomic particles, and organizing a material resource framework at the expense of all others, and becomes a third form of structuring individual action based on the mode of production and how it differentiates individual actors.

That is to say, an individual's interpellation, subjectification, and differentiation within the social class language game that presupposes their being-in-aworld attempts to determine their actions or practical consciousness via the reified language, ideology, etc., of the social class language game, the meaning of which can be deferred via the communicative discourse of the individual actors allowing them to form social groups or heterogeneous communities tied to the dominant social order because of their control of the materials of the material resource framework. Hence, the deferment of meaning in ego-centered communicative discourse of the language and ideology of a social class language game is the final means of determining an individual's action or practical consciousness outside of, and in relation to, its stance, i.e., analytics, vis-à-vis the drives of subatomic particles, drives and desires (anatomy and physiology) of the body and brain, and structural reproduction and differentiation. The (mental) stance of the transcendental ego and the ability to defer meaning in ego-centered communicative discourse within a social class language game are what accounts for the feeling or illusion of free-will.
In other words, whereas the practical consciousness of the transcendental ego stemming from the impulses of embodied subatomic particles are indeterminant as with its neuronal processes involved with the constitution of meaning in ego-centered communicative discourse (Albeit physicists are in the process of exploring the nature, origins, and final states of subatomic particles, and neuroscientists are attempting to understand the role of neuronal activities in developing the transcendental ego and whether or not it continues to exist after death). The form of the understandings and sensibilities of the body and brain are determinant as with structural reproduction and differentiation of the mode of production, and therefore can be mapped out by neuroscientists, biologists, and sociologists to determine the nature, origins, and directions of societal constitution and an individual actor's practical consciousness unfolding.

The interaction of all four elements or structuring processes in relation to the (mental) stance of the transcendental ego of the individual actor is the basis for human action, praxis/practical consciousness, and cognition/mind in a world. However, in the end, consequently, the majority of practical consciousness will be a product of an individual actor's embodiment and the structural reproduction and differentiation of a social class language game given 1) the determinant nature of embodiment, (anatomical and physiological) form of understanding and sensibility of the body and brain amidst, paradoxically, the indeterminacy of impulses of embodied subatomic particles and the neuronal processes involved in ego-centered communicative discourse; and 2) the consolidation of power of those who control the material resource framework wherein a society, the social class language game, is ensconced and the threat that power (consolidated and constituted via the actions of bodies, mode of production, language, ideology, ideological apparatuses, and communicative discourse) poses to the ontological security of an aggregated individual actor who chooses (or not) either ready-to-hand or present-athand to recursively reorganize and reproduce the ideals of the society as their practical consciousness. It should be mentioned that in response to this latter process, those in power positions who internalize the ideals of the social structure and recursively (re) organize and reproduce them as their practical consciousness are in the unready-to-hand stance when they encounter alternative forms of being-in-the-world within their social class language game. They dialectically attempt to reconcile the practical consciousness of their social class language game with the reified practical consciousness of those who have deferred their meanings for alternative forms of being-in-the-world within their social class language. They can either accept, marginalize, or seek to eradicate the deferred or decentered subject or their practices. 
Paul C. Mocombe., J Adv Educ Philos, Feb, 2021; 5(2): 32-51

\section{Phenomenological Structuralism Diagrammatically}

As outlined, phenomenological structuralism agrees with structurationist sociologists that in the constitution of society - which is the reification, by those who control the resources of a material resource framework, of the social relations of production via their bodies (practical consciousness), language, ideology, ideological apparatuses, and communicative discourse - the individual elements incorporate the structure of the whole and get differentiated by the dialectical and relational logic, structural reproduction and differentiation, of that whole. Mocombe's phenomenological structural understanding, unlike that of the traditional structurationists, attempts to provide an analytical tool to explain and examine the relation of the "others" within the totality who do not, however: the relationship between "the individual elements [, who,] internalize [and recursively reproduce,] the structur[ing ideology] of the whole," and those who as a result of their ready-to-hand, unready-to-hand, and present-at-hand stances vis-à-vis the drives of their bodies, residual past consciousnesses (of phenomenal properties) of recycled/entangled/superimposed subatomic particles or through self- reflection or phenomenological meditation in the unready-to-hand and present-at-hand mode of encountering the reified structural terms of a society conceive of, or choose among, fully visible "alternative" ways of being-in-theworld, which they attempt to, antidialectically, exercise in the "totality" at the threat to their ontological security.

This "mechanical" relationship can be expressed diagrammatically (see Figure-5). The model is an adaptation of Stephen Slemon's [33] description of colonialism's multiple strategies for regulating Europe's others [33], and whether in Mocombe's usage of it or Slemon's slightly different depiction, it is a macro, at the societal level, extrapolation of Hegel's and Marx's master/slave dialectical power model, which would proceed along line A1, since they both suppose that their respective concepts (colonialism for Slemon and society, culture, structure, what have you, stemming from the social relations of the mode of production, for me) are ideological or discursive formations constituted through power and power relations reified via mode of production, actions of bodies, language, ideologies, ideological apparatuses, and communicative discourse. Whereas Slemon extrapolates the dialectic to colonialism in particular, Mocombe does so to society in general.

The general understanding, within a phenomenological structural understanding of the constitution of society and practical consciousness, is that individual actors or network of solidarity or cultural groups (irreducibly "mediating" situated subjects), represented by lines " $A$ " and " $B$ " on the diagram, are interpellated and relationally socialized within society-its semiotic field or predefined and predetermined lexicons and representations of signification (at the bottom of the diagram) i.e., the field of socialization "and its investment in reproducing and naturalising the structures of power" [33] through "ideological apparatuses" (at the top of the diagram) controlled by socialized institutional regulators ("As"), power elites or those in power positions, who recursively reorganize and reproduce the rules of conduct (which appear to be natural and commonsensical) of the social structure, which in modern times represent an ideological flanking for the protestant economic (capitalist) subjugation running along line "A1." Where in the first instance (A) there is encountering of the reified rules of conduct of the society (which is its structure, i.e., social structure stemming from the social relations of the mode of production) at the preontological ready-to-hand mode of encountering, there is adoption or internalization (the Structurationist view) on behalf of the individual or network of groups of the prescribed understanding of the representations and practices of the semiotic field, i.e., the recursively organized and reproduced rules of conduct, associated with the social relations of the mode of production, which are sanctioned. In the second (B), the individual encounters the facts and values of the world in either unready-to-hand or the present-at-hand mode, and through a form of phenomenological meditation on the structural terms (i.e., norms, values, prescriptions and proscriptions of power) that presuppose their existence, conceives of, or chooses among other or fully visible alternatives (other "Bs" discriminated by the social structure), a different understanding (, i.e., practical means, arriving from the drives of the body, unconscious drives of recycled/superimposed/entangled subatomic particles, or through the deferment of meaning in ego-centered communicative discourse) of being-in-the-world ; or as in the case of racism, sexism, and classism is prescribed a structurally differentiated unalterable subordinate role based on the relational binary logic (rules for inclusion and exclusion) of the semiotic field of those in power positions ("As"). In this structurally differentiated mode the encountering is always either at the ready-to-hand or unready-to-hand mode of encountering, in the latter because something, discriminatory effects of the totality, is wrong in allowing the social actor to partake in the rules of conduct of the society. So regardless if they accept or reject the rules of conduct, they are still classified by the power elites as (Bs).

The socialized individuals or groups ("As") socialized in the "constitutive power of societal (ideological) apparatuses like education, media, church, family, etc., and the constitutive power of fields of knowledge [, which stems from the semiotic field,] within those apparatuses" (46) — possess the potential to become, if they so choose, power elites and as such institutional regulators (at the top of the diagram), who subordinate through the manufacture of consent. Now to maintain power, those who become regulators (some 
"As") must address "B's" signification, which relationally undermines (it gives social actors an "alternative" form of being-in-the-world), as well as define, delimits, and stabilizes the predefined and reified lexicons and representations of signification that is the society's semiotic field. In other words, their ("Bs") interpretations or structurally differentiated identity in relation to "A's" reject the singularity and realism or naturalism attached to the representations and meanings of the social field, while at the same time helping to constitute it by defining, delimiting, and stabilizing the field, i.e., "B's" interpretation in relation to "A's" helps to define, because it is not, "A's" interpretation. Hence, the "As" must negotiate, appropriate, and reinflect "Bs" interpretive-practices into the semiotic field in order to delimit, their own; this is done, or has been done, up to this point in the human archaeological records on the constitution of society, by having them ("Bs") remain outside the field, by dismissing their interpretive-claims, in which case the field justifies their permanent outsider status (oppressed or discriminated against minorities, i.e., marginalized "other").

The "Bs," for the most part, can either accept (if their gaze is upon the eye of power-"As"- - for recognition as a structurally differentiated "other," i.e., a class-in-itself) their appropriation, the rationale the institutional regulators ("As") prescribe to their ("B ${ }_{1} \mathrm{~s}$ ") interpretive-practical consciousness which legitimates it as a representation, or they (" $\mathrm{B}_{2} \mathrm{~s}$ ") may choose (by averting their gaze as a class-for-itself) to remain quasioutsiders if the meaning disclosed by the dominant institutional regulators is not in accordance with their own, or a previously discriminated subculture's, interpretive-practical understanding of the signifiers of the social structure. Regardless of what choice they ("Bs") make, however, they, "Bs," because the validity claims the institutional regulators provide for their (Bs') understanding validates their existence to start with, constantly attempt incorporation and acceptance, either, as a "class-in-itself," pushing for integration as a structurally differentiated "other" (hybrid) who recursively reproduce the rules of conduct of the social structure (" $\mathrm{B}_{1} \mathrm{~s}$ ")) ; or separation (" $\mathrm{B}_{2} \mathrm{~s}$ "), as a "classfor-itself," for their own rules of conduct which are sanctioned by the power elites of the subculture. The former is the position of the bourgeoisie's of once discriminated against groups, such as blacks, women, etc., in contemporary postindustrial Protestant capitalist societies seeking to partake as an hybrid other in the social class language games of the society.

Thus there are two fundamental paths which are open to "Bs": first, if they (B) accept the understanding of (A), regarding their interpretation as an "other," and seek integration, as a structurally differentiated "class-in-itself," they have to give up their interpretive-practical consciousness, which on the one hand undermines the legitimation of the interpretive community they are classed with, while on the other hand, legitimating society's semiotic field, which has appropriated their ("Bs"") understanding and representation to substantiate and delimit their (As') power position and "practical consciousness." From this perspective, the "Bs," "B $\mathrm{B}_{1}$ "”, who accept appropriation, are socialized (institutionalized) and attempt to live as ("As"), which entail recursively organizing and reproducing, as a hybrid "other," the rules of conduct of the society which are sanctioned. Those who do not (the second path), that is, those in the present-at-hand mode of encountering who reject the rules of conduct of the society, for their own, " $\mathrm{B}_{2} \mathrm{~s}$ ", may seek to reconstitute society in line with their interpretive-practical consciousness, which gives rise to another (warring) structure of signification or form of being-in-the-world, which, as a segregated categorical boundary or alternative practical consciousness, relationally and differentially delimits that of the society or social structure, which they initially constituted.

From the perspective of power, "As," "Bs"” interpretations, their interpretive-practical consciousness, are always represented in the semiotic field in order to define, delimit, and stabilize the power structure. Thus, "Bs" are always oppressed minorities or majorities, i.e., "others," in the Hegelian master/slave relationship (A1), who must construct their identities or consciousness within two or more ideals: that of the social structure (master's own understanding of themselves) and what it says of the discriminated against "other" (the slave). Hence, the "Bs," as long as their gaze is turned back upon the eyes of power (vector of motion of " $\mathrm{B}_{1} \mathrm{~s}$ ") for recognition in the unready-tohand mode of encountering, which seeks to fix the status quo for their participation, pose no real danger to the semiotic field, unless-following the aforementioned second path," $\mathrm{B}_{2} \mathrm{~s}$,", - they should takeup arms against it as a distinct structuring structure, i.e., "class-for-itself" or categorical boundary, which has averted their gaze, and are attempting to preserve or universalize their "alternative" ontology or "practical consciousness." This latter position is represented by Islamic fundamentalists contemporarily, and the African participants of Bois Caiman during the Haitian Revolution (1791-1804), for examples.

In other words, in having to construct their (Bs) identities or consciousness by warring against the ideals of the social structure, which become the relational terms that defines, delimits, and stabilizes the social structure and that by which all ("As" and "Bs") must construct their consciousness, the gaze back upon the eye of power is a sign of recognition of the validity claims of the social structure, which necessarily implies that in order to be recognized the "Bs" must attempt to be what they are not, like "As." This agential move to be like "As," however, constrains the variability of practices, which, as the diagram highlights, can only be maintained if the gaze of Bs' (vector of motion of 
" $\mathrm{B}_{2} \mathrm{~S}$ "") are averted away from the eyes of power in order to establish another segregated structuring structure, which celebrates and reproduces the practices' of their "otherness." So long as the aim of "B" is for acceptance into the structure of social relations that constitute the society, their "otherness" can only be expressed as those ("As") who recursively reorganize and reproduce the rules of conduct of the social structure. For it is only upon the world of existing state of affairs, i.e., the valid norms and subjective experiences of power (the structure of the conjuncture of the social relations of production), which is taken to be the nature of reality and existence as such, will they ("Bs") be admitted into the structure of social relations that constitute the society, for any other form may undermine the whole of social relations that is the constituted society.

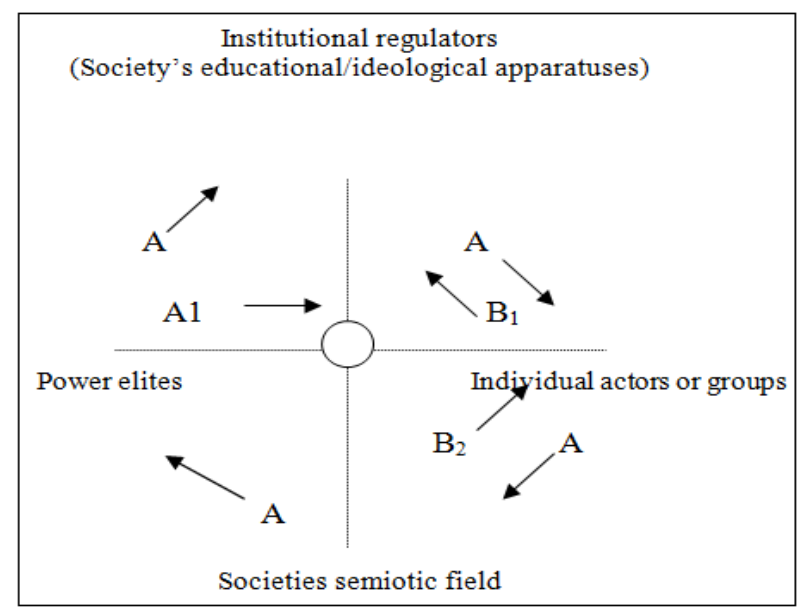

Fig-5

Figure-5 Diagram representing the nature of the relationship between society and the individual or group in phenomenological structuralism. " $\mathrm{A}$ " represent the power elites of the social structure; $B_{1}$ represent those "others" (hybrids) with their gaze upon the eye of power seeking to be like "A"; $B_{2}$ represent those with their gaze averted from the eye of power seeking to exercise an alternative practical consciousness from that of "As" and "B $\mathrm{B}_{1}$."

\section{The Role of Power in the Diagram}

Whereas, Figure-5 demonstrates the action of individual actors or groups within "a" reified consciousness, social class language game, that forms the structure of relations that is their society via the practical consciousness of bodies, language, ideology, ideological apparatuses, communicative discourse, and mode of production; Figure 6 makes evident the actions of social actors (As), if and when, they become institutional regulators or power elites.

The understanding here is that it is the legal regulations of a society, its "lexicons and representations of signification," its rules of conduct that are sanctioned, as outlined by the power elites, or institutional regulators in power positions, which represent the objective conditions (social structure) of society that structure the social relations of the mode of production and constitute the materials by-which consciousness is to be cultivated for the ontological security of the individual. In other words, the general understanding, within a phenomenological structural understanding, is that individual actors or groups (irreducibly situated subjects), lines $\mathrm{A}$ and $\mathrm{B}$, are socialized within society-its semiotic field or predefined and predetermined lexicons and representations of signification (at the bottom of the diagram) i.e., the field of socialization "and its investment in reproducing and naturalising the structures of power" [33] — through "ideological apparatuses" (at the top of the diagram) controlled by socialized institutional regulators ("As"), which represent an ideological flanking for the economic subjugation running along line "A1." The relation between the two runs this way: societal power operates through a complex relationship between apparatuses (i.e., the law, education, rituals, family etc.) placed on line "C," where in the first instance institutional regulators ("As") — at the top of the line - appropriate and manufacture, based on what is already understood, lexicons and representations of signification of individuals in order to consolidate and legitimate itself as a natural "order" and to reproduce individuals as deployable units of that order. So, in the first instance, societal power runs not just through the middle ground of this diagram (A1) but through a complex set of relations happening along line " $\mathrm{C}$;" and since the argument here is that a function (i.e., socialized social actor) at the top of this line is employing those representations created at the bottom of the line in order to make up "knowledges" that have an ideological function, one can say that the vector of motion along line $\mathrm{C}$ is an upward one, and that this upward motion is part of the whole complex discursive structure whereby society manufactures individuals and thus helps to regulate societal relations. This is the first position.

The second position, as the diagram demonstrates, is the downward movement of societal power, where the institutional regulators of society's apparatuses are understood to be at work in the production of a purely unique and entirely projected idea of the individual, relationally delimited by other fully visible marginalized "alternative" forms of the individual being-in-the-world. The point this movement, which is inextricably tied to the first, is trying to articulate is that society is a product of the working and reworking of reified psychic projections associated with the social relations of the mode of production operating through line A1. Hence, society has to be understood as a structure or system of power relations in which those in power positions attempt to structure, via bodies, language, ideology, ideological apparatuses, and communicative discourse individuals toward an unchangeable unified end associated with the social relations of the mode of production. This does 
Paul C. Mocombe., J Adv Educ Philos, Feb, 2021; 5(2): 32-51

not mean that there is no agency, for who or what acts oppositionally, in this understanding of the constitution of society, is demonstrated through an understanding of the movements of lines A and B described above, which represents the Haitian concept of antidialectics.

Essentially, then, in this phenomenological structural understanding, society develops from the interpretive-practical consciousness of those (power elites or social actors in power positions) who maintain control of and integrate its material resource framework via the social relations of the mode of production. Through this economic and political process, all individual actors ("As" and "Bs"), unless they choose (as a "class-for-itself" under the auspices of their own power elites) to, antidialectically, establish their own institutions, are socialized in apparatuses controlled by these social actors, institutional regulators (at the top of the diagram), who employ their representations, the reified symbolic objects that constitute the semiotic field (society) - at the bottom of the diagram, in institutions - so as to control, guide, and incorporate the ambivalence that lies in the act of interpretation [34] in order to make up and reproduce ideological "knowledges" that maintain the functioning of the society as a whole. Mocombe is arguing that this model, up to this point in the human archaeological research on societal relations, is a general structure for understanding the multivalent strategies at work in the reproduction and transformation of societies. Furthermore, it resolves the issue of agency, which is problematic when one posits ideology or discourse or psychic processes as constructing human subjects, for who or what acts is clearly demonstrated in the model through the praxis of the structure ("As") and antistructural elements ("Bs" if they form interpretative communities, " $\mathrm{B}_{2} \mathrm{~s}$ ", which, antidialectically, do not seek incorporation or cooptation).

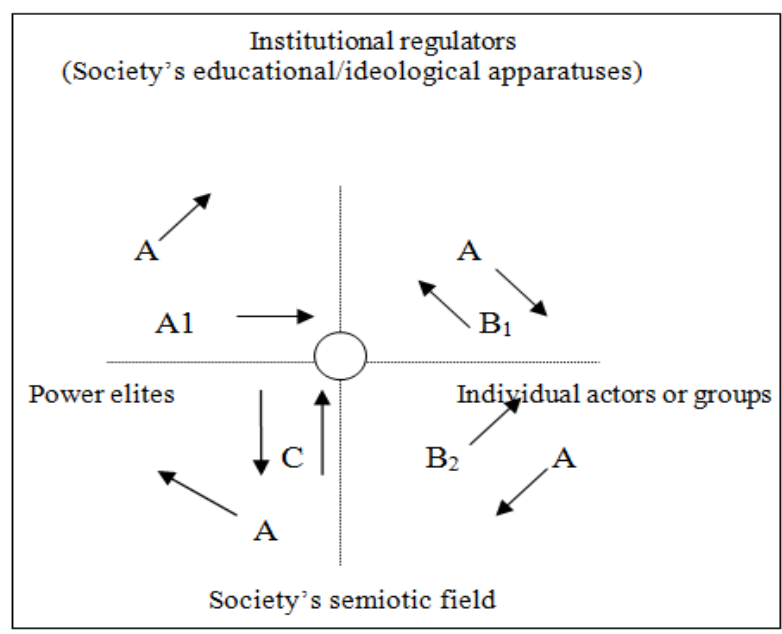

Fig-6

Figure-6 Diagram representing the nature of the relationship - $\mathrm{C}$ - between society's semiotic field (bottom of diagram) and the institutional regulators (top of diagram) in phenomenological structuralism

\section{REFERENCES}

1. Lévi-Strauss, C. (1963). Les discontinuités culturelles et le développement économique et social. Social Science Information, 2(2), 7-15.

2. Bell, T. H. (1985). Deformation partitioning and porphyroblast rotation in meta- morphic rocks: a radical reinterpretation. Journal of Metamorphic Geology, 3(2), 109-118.

3. Bell, D. E. (1982). Regret in decision making under uncertainty. Operations research, 30(5), 961-981.

4. Parsons, T. (1951). Illness and the role of the physician: a sociological perspective. American Journal of orthopsychiatry, 21(3), 452.

5. Althusser, L. (2001). Lenin and Philosophy and Other Essays. New York: Monthly Review Press.

6. Althusser, L., \& Étienne, B. (1970). Reading Capital (Ben Brewster, Trans.). London: NLB.

7. Ortner, S. (1984). Theory in Anthropology Since the Sixties, Comparative Studies in Society and History, 26:126-66.

8. Crothers, C. (2003). Technical Advances in General Sociological Theory: The Potential Contribution of Post-Structurationist Sociology. Perspectives, 26(3), 3-6.

9. Bourdieu, P. (1990). Social space and symbolic power. In In Other Words, Polity Press.

10. Bourdieu, P. (1980). Le capital social: notes provisoires. Actes de la recherche en sciences sociales, 31(1), 2-3.

11. Bourdieu, P. (1984). Distinction: A social critique of the judgement of taste. Harvard university press.

12. Sahlins, M. (1976). Notes on the multiple structures of history and praxis in Moala. Journal de la Société des Océanistes, 32(50), 7-29.

13. Sahlins, M. (1995). How" natives" think: about Captain Cook, for example. University of Chicago Press.

14. Sahlins, M. (1981). The stranger- king or Dumézil among the Fijians.

15. Anthony Giddens. (1984). The constitution of society: Outline of the theory of structuration. Univ of California Press.

16. Habermas, J. (1987). The Philosophical Discourse of Modernity, trans. F. Lawrence. Cambridge, MA: Massachusetts Institute of.

17. Habermas, J. (1981). Reason and the Rationalization of Society. Beacon Press.

18. Habermas, J. (1984). Mudança estrutural da esfera pública: investigações quanto a uma categoria da sociedade burguesa (Vol. 357). Rio de Janeiro: Tempo Brasileiro.

19. Archer, M. S. (1985). The myth of cultural integration. British Journal of Sociology, 333-353.

20. Mocombe, P. C. (2016). The Vodou Ethic and the Spirit of Communism: The Practical Consciousness of the African People of Haiti. Maryland: University Press of America. 
Paul C. Mocombe., J Adv Educ Philos, Feb, 2021; 5(2): 32-51

21. Mocombe, P. C. (2014). Against critical race theory. Ethnic Studies Review, 37(1), 83-106.

22. Mocombe, P. C. (2017). The Protestant Ethic and the Spirit of Capitalism; and the Vodou Ethic and the Spirit of Communism. Sociology, 51(1), 76-90.

23. Sayer, D. (1987). The violence of abstraction: The analytic foundations of historical materialism.

24. Mocombe, P. C., Tomlin, C., \& Wright, C. (Eds.). (2013). Race and class distinctions within Black communities: A racial-caste-in-class. Routledge.

25. Mocombe, P. C. (2015). Postindustrial capitalism and the problems with Bourdieu's social and cultural capital in understanding the Black/White achievement gap in the United States and United Kingdom. Citizenship, Social and Economics Education, 14(3), 203-217.

26. Mocombe, P. C. (2018). The death of Imhotep: A hermeneutical framework for understanding the lack of Black males in STEM fields. Education and Urban Society, 50(1), 38-55.

27. Mocombe, P. C. (2019). The Theory of Phenomenological Structuralism. United Kingdom: Cambridge Scholars Publishing.
28. Hameroff, S., \& Roger, P. (2014). "Consciousness in the Universe: A Review of the 'Orch OR' theory." Physics of Life Reviews, 11: 39-78.

29. Randall, L., \& Sundrum, R. (1999). Large mass hierarchy from a small extra dimension. Physical review letters, 83(17), 3370.

30. Gauthier, R. (2020). "Big Bangs Created by Univon Particles from a Conscious Quantum Field-Towards the Next Scientific Revolution," retrieved from https://www.academia.edu, accessed 1 April 2020.

31. Anderson, T. (2020). "The Big Bang may be a Black Hole Inside Another Universe," retrieved from www.medium.com, accessed 27 July 2020.

32. McFadden, J. (2020). "Integrating Information in the Brain's EM Field: the cemi Field Theory of Consciousness", Neuroscience of Consciousness 6 (1): 1-13.

33. Slemon, S. (1995). Afterword: the English side of the lawn. Essays on Canadian Writing, (56), 274.

34. Bhabha, H. K. (1995). Cultural diversity and cultural differences. Na. 